\title{
ГОСУДАРСТВЕННАЯ МОДЕЛЬ СОДЕЙСТВИЯ РЕАЛИЗАЦИИ СОЦИАЛЬНОЙ ОТВЕТСТВЕННОСТИ УНИВЕРСИТЕТОВ
}

\author{
(C) 2021 Булгакова Маргарита Андреевна \\ ассистент на кафедре экономики и управления \\ Владивостокский государственный университет экономики и сервиса, Россия, Владивосток \\ E-mail: margarita.bulgakova@vvsu.ru \\ Author ID 1023984 \\ SPIN 6077-3189 \\ ORCID 0000-003-3543-2818
}

В статье рассмотрены уровни нормативно-правового регулирования сферы высшего образования, в рамках которых формируются программы государственной поддержки университетов, направленные на содействие реализации их социальной ответственности. На основании данных положений была предложена модель, отражающая основные экономические инструменты воздействия на позитивный вклад в развитие регионального сообщества. В рамках настоящего исследования определены эффекты на развитие практики социальной ответственности образовательными организациями высшего образования, в связи с чем выявлены возможные конкурентоспособные преимущества на рынке образовательных услуг.

Ключевые слова: высшее образование, университет, социальная ответственность, конкурентоспособность, рынок образовательных услуг, государственная политика.

Эффективность деятельности университетов определяется по множеству критериев, но главным образом это содействие в решении региональных проблем, к которым относят: отток населения, снижение уровня безработицы, повышение уровня благосостояния и прочие. На реализацию программ, направленных на развитие регионального сообщества, университету требуется совокупность материальных и нематериальных ресурсов, но в нынешних экономических условиях не все вузы располагают возможностью, поскольку финансирование осуществляется в соответствии с федеральным законом от 29.12.2012 № 273-Ф3 «Об образовании в Российской Федерации» [1], а также за счет привлеченных средств от образовательной, научной и иной деятельности. В большей степени на реализацию социальной ответственности университет выделяет привлеченные средства из внебюджетных фондов, поскольку исходя из принципов социальной ответственности, основополагающим является добровольный вклад в развитие общества. Несмотря на данный факт, социальная ответственность университета носит определенные специфичные характеристики, среди которых выделим следующие:

- во-первых, университет является центром социализации;
- во-вторых, стабилизация социальноэкономических отношений;

- в-третьих, формирование человеческого капитала.

Стоит отметить, что в Российской Федерации деятельность университетов жестко регламентирована и контролируется органами власти всех уровней.

Таким образом, деятельность университетов, учредителем которых является Министерство науки и высшего образования Российской Федерации, четко регулируется государством.

За последние годы конкуренция на рынке образовательных услуг усложнила ситуацию: требования со стороны общества постоянно формируют новые стандарты, соответствие которым требует дополнительной финансовой нагрузки. В этих условиях органы государственной власти утверждают программы содействия развитию образовательного сектора экономики, которые помогают университетам реализовывать социальную ответственность.

В рамках данного исследования была предложена модель государственной политики содействия реализации социальной ответственности, представленной на рисунке 1 .

Представленная модель отражает в первую очередь реалии международного образователь- 


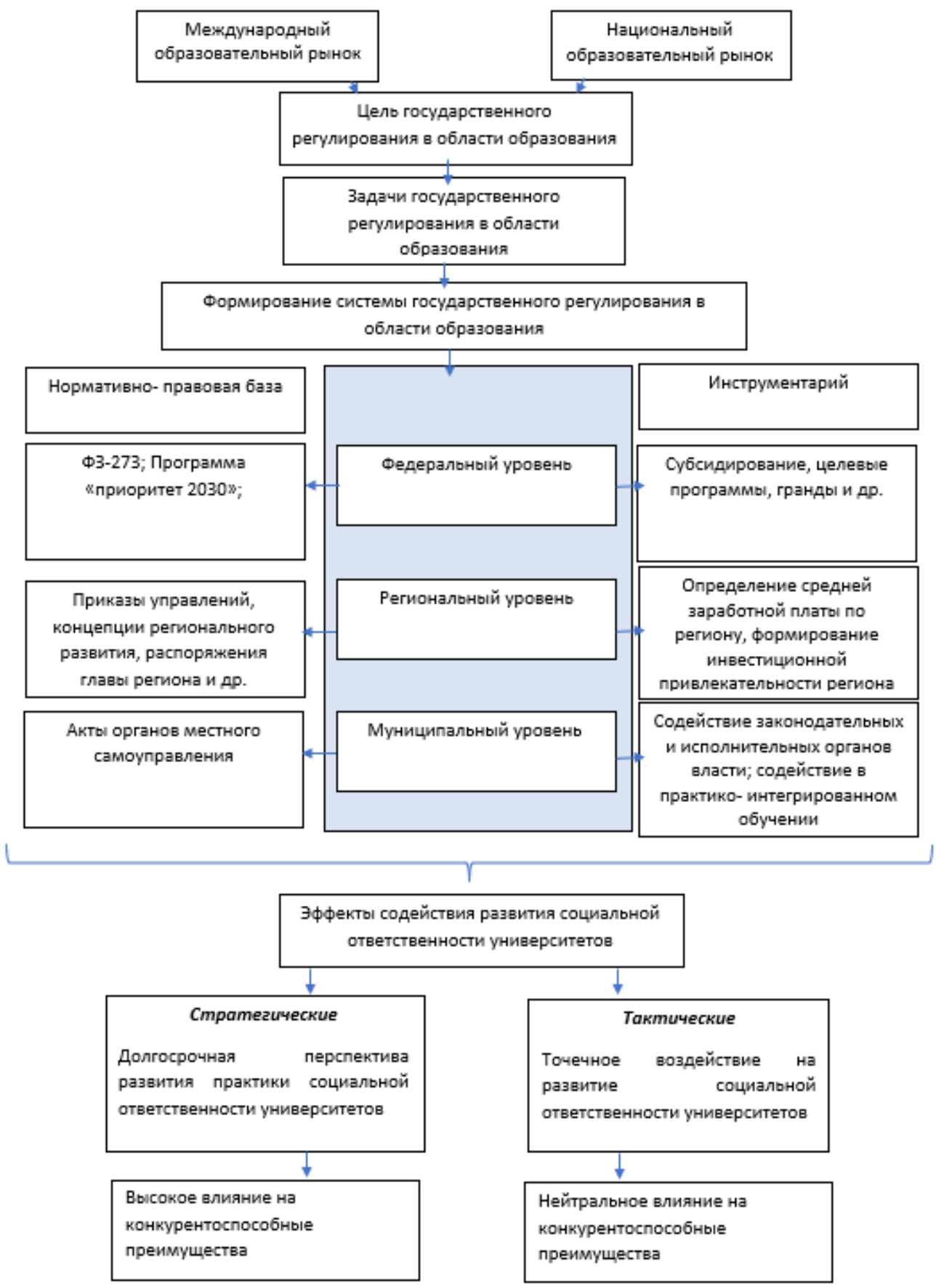

Puc. 1. Модель государственной политики содействия реализации социальной ответственности университетов

ного рынка, поскольку в сложившихся условиях определяющим фактором эффективности деятельности образовательной организации высшего образования является соответствие международным образовательным стандартам. Университеты, отвечающие мировым требованиям, занимают соответствующие позиции в глобальных рейтингах, что характеризует не только статус отдельно взятого вуза, но и национальную образовательную систему.

Требования национального образовательного рынка определяются тенденциями развития страны и учитывают глобальные изменения общества, в соответствии с чем органы законодательной и исполнительной власти формируют условия для успешной реализации деятельности 
университетов. В связи с чем основной целью государственной политики содействия развитию социальной ответственности является создание оптимальных условий деятельности университета для реализации образовательных, научноисследовательских и социальных программ, направленных на удовлетворение потребностей общества.

В рамках достижения поставленной цели необходимо решить комплекс таких задач как:

1. Создание системы кадров для воспроизводства экономики страны;

2. Развитие инфраструктуры;

3. Повышение качества и доступности образовательных услуг;

4. Возрастание значимости человеческого капитала в экономике и прочие.

Наиболее продуктивное решение определенных задач достигается путем создания системы государственного регулирования, которая представляет многоуровневую сеть нормативно-правовых актов, а также широкий спектр инструментов, направленных на содействие развитию социальной ответственности университетов.

В российской практике выделяют основные уровни нормативно-правового регулирования по охвату действия. Так на федеральном уровне рассматриваются акты обязательные для исполнения на всей территории России, в отношении образовательного сектора экономики относят в первую очередь Федеральный закон № 273-Ф3 «Об образовании в Российской Федерации», также относят постановления Правительства, указы президента. К нормативно-правовой базе субъектов Федерации относят акты, распространяющиеся на резидентов данного региона. Рассматривая муниципальный уровень регулирования, относят акты местного самоуправления, а именно постановления органов местного самоуправления.

Исходя из каждого уровня регулирования формируется практический инструментарий, способствующий развитию социальной ответственности университетов. На сегодняшний день наиболее актуальной федеральной программой развития университетов является «Приоритет-2030», в соответствии с которой на конкурсной основе предоставятся гранты на развитие вузов. Один из основных инструментов содействия развитию социальной ответственности также относят субсидирование, однако на практике он применяется в большинстве случаев к ведущим университетам страны, а образовательные организации высшего образования, не обладающие таковым статусом, не могут рассчитывать на поддержку со стороны государства.

В развитии национальной экономики одной из главных задач благосостояния России является развитие науки и технологий. В рамках данного положения Правительством Российской Федерации был разработан и принят национальный проект «Наука и университеты», в основе которого лежат такие инициативы как:

1. Интеграция. Создание интегральных научно-исследовательских и производственных структур, которые будут отвечать требованиям мирового масштаба. Данная инициатива позволит объединить ресурсы стейкхолдеров и увеличит коммерциализацию научных разработок.

2. Исследовательское лидерство. Под воздействием научно-технологического развития планируется создать на базе ведущих университетов тематические центры науки, что позволит увеличить трансфер технологий и как результат достичь значимых результатов в стратегическом научно-технологическом развитии России.

3. Развитие инфраструктуры. Для достижения целей национального проекта необходима модернизация оборудования и обновление приборной базы, что позволит создать комфортные и современные условия как для персонала, так и для обучающихся.

4. Кадры. Данная инициатива направлена на развитие человеческого капитала региона, создание кадрового резерва для отраслей, отвечающим запросам экономики региона. Одним из показателей данного проекта является доступность высшего образования, что в соответствии с паспортом должно соответствовать 50\% бюджетных мест от общего числа обучающихся по очной программе бакалавриата. Также необходимым условием является создание привлекательных условий труда для молодых ученых в возрасте до 39 лет и обеспечение кадрового состава таковыми специалистами минимум на 44\% от общего профессорско-преподавательского состава университета [2].

Инициативы национального проекта «Наука и университеты» неразрывно связаны между собой и только равномерное выполнение вышеизложенных положений приведут к достижению основополагающей цели: увеличение универ- 
ситетов, участвующих в программе стратегического академического лидерства, а также повышения значимости российского образования на международном образовательном рынке.

Вопросы, связанные с нормативно-правовой базой, определяющей регулирование на региональном уровне, рассматриваются в таких актах как: региональные законы и законопроекты в отношении субъекта, программы комплексного развития, концепции развития регионов, положения об органах управления и другие. В частности, рассматривая Дальневосточный федеральный округ, в отношении субъектов реализуются программы, направленные на сокращение оттока населения, развития инфраструктуры регионов, ускорение экономического роста и технологического развития, повышения их инвестиционной привлекательности, а также повышение уровня благосостояния населения, в чем способствуют университеты, реализуя социальную ответственность [3].

Так для реализации национальных проектов «Образование» и «Наука и университеты» главами субъектов федерации разрабатываются и принимаются постановления о развитии образования. На примере Приморского края (далее ПК) рассмотрим постановление правительства ПК «Развитие образования приморского края» от 16.12.2019 № 848-па. Основной задачей развития образования в Приморском крае является усиление в долгосрочной перспективе с 2020 г. по 2027 г. вклада образования в социальноэкономическое развитие региона, удовлетворение потребностей населения в получении доступных и качественных образовательных услуг. Особой актуальностью настоящего Постановления является социализация обучающихся, поскольку данный регион является поликультурным и многоконфессиональным, в соответствии с чем в образовательный процесс должны быть интегрированы социокультурные ресурсы религии, экономики, психологии и политики. Ключевой позицией развития образования ПК ориентированы на формирование здорового и безопасного образа жизни обучающихся [4].

На муниципальном уровне в нормативноправовых актах закрепляются положения о регулировании взаимоотношений с органами местной власти. В частности, акты и их изменения, принятые Думой муниципального образования. На данном уровне в большей степени рассматриваются вопросы взаимной деятельности университета и муниципалитета и направления совместных сил на решение общественных проблем.

В сложившихся реалиях финансирования образовательных организация высшего образования, как определяющего инструмента поддержки вузов, существует практика финансирования университетов не только из федерального бюджета, но регионального и местного, однако по данным мониторинга эффективности деятельности образовательных организаций высшего образования данный инструмент слабо развита или отсутствует вовсе в отношении университетов, удовлетворяющих условия выборки. На основании рассмотренных уровней нормативно-правового регулирования системы образования, а также инструментов содействия развитию социальной ответственности университетов формируются эффекты, воздействующие на деятельность вуза.

Стратегическое содействие в деятельности университета определяется долгосрочным влиянием на развитие социальной ответственности, что характеризуется высокой адаптивностью вуза к сложившимся условиям деятельности на рынке образовательных услуг и формирует конкурентоспособные преимущества в долгосрочной перспективе.

В свою очередь, тактическое содействие нормативно-правового регулирования определяет точечное воздействие на реализацию социальной ответственности вуза и позволяет оперативно использовать условия внешней среды. Краткосрочное воздействие на стейкхолдеров не приводит к повышению общих преимуществ на рынке, однако системное положительное влияние на региональное сообщество повышает статус университета среди пользователей его услуг.

В российской практике поддержке университетов, которая позволяет в большей степени реализовать социальную ответственность, направлена на ведущие университеты. Государственные программы развития и поддержки ориентированы на создание конкурентоспособной образовательной среды не только в национальных, но и в мировых масштабах. В сложившихся реалиях университеты, не имеющим такового статуса, зачастую не справляются с возлагаемыми обязательствами, поскольку поиск альтернативного финансирования для реализации социально-значимых мероприятий 
сложный административный процесс.

Более гармоничного развития регионов Дальнего Востока можно достичь путем формирования равномерного распределения средств бюджетной системы РФ, направленных на поддержку высших учебных заведений. Поскольку социальная ответственность в современном обществе является неотьемлемой частью функционирования хозяйствующего субъекта, соответственно необходимо создание четких стандартов для образовательных организаций высшего образования.

Подводя итоги, стоит отметить, по мере раз- вития значимости социальной ответственности в деятельности организаций, встает вопрос о целесообразности представления социальной отчётности. В международной практике давно закрепился отчет о социальной ответственности как один из важнейших инструментов взаимодействия со стейкхолдерами и показатель открытости хозяйствующего субъекта экономики [5]. В российских реалиях предоставление информации является добровольным, однако все больше заинтересованных пользователей отдают предпочтение сотрудничеству с социальноответственными организациями.

\section{Библиографический список}

1. Федеральный закон «Об образовании в Российской Федерации» от 29.12.2012 N 273-ФЗ. [Электронный ресурс]: http://www.consultant.ru/document/cons_doc_LAW_140174/8f0d1d79be2a396d03ccc8425a2b8cd70748 1d93/. Доступ из справ.-правовой системы «КонсультантПлюс».

2. Национальные проекты. Наука и университеты [Электронный ресурс]. - Режим доступа: https:// xn-80aapampemcchfmo7a3c9ehj.xn - p1ai/projects/nauka-i-universitety.

3. Распоряжение Правительства РФ от 24.09.2020 № 2464-p [Электронный ресурс]. - Режим доступа: http:// static.government.ru/media/files/NAISPJ8QMRZUPd9LIMWJoeVhn1l6eGqD.pdf.

4. Постановление от 16 декабря 2019 года N 848-па Об утверждении государственной программы Приморского края «Развитие образования Приморского края» на 2020-2027 годы» [Электронный ресурс]. - Режим доступа: https://docs.cntd.ru/document/561664333.

5. Груздева Н.Р. Социальный отчет как один из основных этапов социального аудита организации // Вестник евразийской науки. 2013. № 3 (16). URL: https://cyberleninka.ru/article/n/sotsialnyy-otchet-kak-odin-izosnovnyh-etapov-sotsialnogo-audita-organizatsii (дата обращения: 14.08.2021). 